\title{
Trauma Management on the Battlefield: A Modern Approach
}

\author{
Lt Col A Hawley \\ OBE, MB, ChB, RAMC \\ Chief Instructor
}

Defence Medical Services Training Centre, Keogh Barracks, Ash Vale, Aldershot, GU12 5RQ

SUMMARY: With the development of British Army doctrine it is necessary to review the concepts underlying medical support to the modern battlefield. In particular, the provision of timely and balanced resuscitation to the high intensity battle is an issue requiring an understanding of both the tactical and the clinical demands. The $\mathrm{c}$ wholesale application of civilian techniques and approaches to trauma management is not possible given the $\overrightarrow{0}$ austerity of the battlefield clinical environment. The commitment to excellence and quality of care implicit inmodern mainstream practice is of continuing relevance to the battlefield. A doctrinal approach involving the $\vec{\omega}$ definition of desired clinical outcome and the constraints of operational feasibility, is proposed. Specifically, the introduction of a triad approach to trauma management is offered. The triad comprises readily available 3 Battlefield Advanced Trauma Life Support (BATLS) skills, Surgical Resuscitation deployed forward and the provision of Field Intensive Care. Such an approach would marry together the clinically ideal with the tactically

\section{Introduction}

It has become a truism to state that much has changed during the decade of the $90 \mathrm{~s}$. The entire strategic environment of Europe has been re-ordered and this has been matched by similar fundamental changes in the rest of the world. The certainties of the bi-polar stand-off between NATO and the Warsaw Pact have been replaced by the intricacies of a new multi-polar world order. However unpalatable they may have been, the difficulties of managing the strategic stalemate of the Cold War presented many quantifiable and predictable factors which helped to preserve the peace. It also provided a sense of security, notwithstanding the ever present threat of a nuclear exchange, since the opposing positions were based on mutual deterrence and this was recognised by both major partners as the relationship matured(1). Those certainties have now been replaced by a complex series of regional conflicts, many of them fierce and bloody affairs, and a matrix of intra-state confrontations which seem to be both intractable and perennial (2).

This changed security climate is matched by fundamental alterations in medical and health care provision. In particular, developments in the management of trauma had moved apace. The introduction of Advanced Trauma Life Support (ATLS) protocols and philosophy has been a major advance in the improvement of the standard of care available to trauma patients. Similarly, the accompanying availability and capability of new medical technologies has profoundly affected the standard and quality of care. Expectations and capabilities continue to increase.

Not only have these professional approaches and philosophies altered but the context in which they are likely to be applied has also radically changed. The Armed Forces have been restructured and, as part of this, the Defence Medical Services have also undergone fundamental reorganisation. The overall defence posture is still cast in the traditional defence roles 1,2 and 3 (3), but the way in which these roles are planned to be 8 fulfilled has altered. Manoeuvre warfare is now theo accepted doctrinal basis for the application of combert power on the high intensity battlefield. The implicationso of this are central to the future provision of medicalo support. Unfortunately, with the necessary concentrati\&n on the restructuring required by the Defence Costs Stud, the opportunity to quantify and assimilate thesece implications has not been forthcoming. The doctring basis for medical support to the future high intens battlefield still remains obscure. This paper will seek address that need.

\section{The Casualty Factor}

Despite the recent growth in study of quantifiable $\overrightarrow{\vec{B}}$ factors in war, the intangible human factor remains the 3 basic common denominator. At essence, war is waged in men's minds for men's minds. It is still as true today aso ever that "War is a act of human intercourse"(4) Equally, "Man, not men, is the most important consideration"(5) The idea that the human element is fundamental to the whole business of waging operations is so obvious that it seems unnecessary to restate it. However, it does stand@ restating given the absolute importance of the proposition.

Yet, that human element has subtly changed. A윽 comparison of the contemporary British soldier with his predecessor of August 1914 would illustrate this point? nicely. The soldier of the First World War had a number of certainties; God was in His heaven, the British Empire? was the greatest civilising influence the world had seen, the King was right and the Hun was evil. In simple terms, this was believed by many(6). Now many of thoses personal certainties have disappeared for the modern $N$ soldier. Instead, he is very conscious of his own mortality and frailty when faced with the loneliness of the battlefield(7). Additionally, his acquaintance with death is 
very intermittent and infrequent. Death is something which happens to others, not to the young. Whereas his forefathers were well acquainted with death by virtue of the high infant mortality rates, prevalence of infectious disease and poor therapeutic facilities, the modern serviceman has not been exposed to these factors.

Indeed, the soldier is surrounded by evidence of enhanced medical capability. It is commonplace to read of transplants, reconstructive surgery, breakthroughs in treatments and accessibility of care. The prevailing climate can be interpreted by the layman as the omnipotence of medicine $(8,9)$. In addition, the Patient's Charter makes the point that the confidence is timely and high quality treatment are a perfectly reasonable expectation of a citizen of the United Kingdom. As a soldier, he may well have completed an operational tour of Northern Ireland, where the sustaining of a casualty by a foot patrol necessitated the abandonment of the mission and introduced a new imperative to get the injured to the nearest casualty department. This would be no more than 30 minutes away from the point of wounding given the geography of the province.

Such an experience serves to reinforce perceptions of the exceptional speed and quality of resuscitation achieved by the US Army in Vietnam(10). The sight of a helicopter dustoff still sends an evocative and powerful message, promising speedy treatment and relief from the chaos and violence of the battlefield. It marries up with the dramatic imagery of civilian helicopter ambulances being used in everyday civilian emergency care. The aggregate effect is to perpetuate and legitimise the soldier's expectation of high quality and immediately available trauma care.

All of the these aspects are implicitly recognised in the new doctrine for the British Army. Casualties are highlighted as a constraint on operations and therefore, a concept of operations which accommodates this and reduces the casualty rate is encouraged. An implication of this factor is that, not only should casualty rates be kept low but that the quality of care available to the casualties should be high. Any failure to achieve this might possibly not only lead to an adverse effect on the soldier's morale, it could also have implications for popular support for the operation. With the threat of general war involving nuclear release now having receded, we have entered a new age of limited war and myriad short term commitments. Many of these conflicts and deployments will be on behalf of the UN with a less obvious aspect of national interest involved. Accordingly, there is likely to be a lower tolerance of casualties by the public. Recent US experience in Somalia underlines this point(11). Once more, the quality and immediacy of the medical care become important elements of the overall strategy.

Providing an external audit on all battlefield performance is the media. By nature sceptical and enquiring with the capability to research interest thoroughly, the media play an important role in opinion

formation $(12,13)$. This is of central significance to a democratic government ultimately responsible to an electorate. It is also of crucial importance for military commanders, raising the perennial challenges of retaining operational security whilst maintaining popular support(14). Within the military, the medical services will be especially attractive to the media because of the nature of their work. Casualties assume a political significance in limited war as well as providing good human interest stories. Recent operational experience confirms that the media will target medical facilities. This interest may assume the nature of an audit procedure measuring performance against expectation, with obvious adverse results given any shortfall.

\section{Changes in Operational Context}

In the Medical History of the Second World War, Sir WH Ogilvie described surgical advance as follows, "There are, however, three aspects to the matter, advances in surgical method, advances in accessory methods that help surgery, and improvements due to altered conditions of warfare. Of these the last is most important, the first the least."(15) This is a crucial point. It is the context in which medicine is practised which is the decisive factor determining clinical outcome. It is precisely that context which has fundamentally changed.

The publication of British Military Doctrine(16) signalled the introduction of a written doctrinal basis for the exercise of military power, as illustrated in Figure 1. It

Humanitarian Operations

Peace Keeping

Peace Enforcement

Low Intensity

Mid Intensity

High Intensity

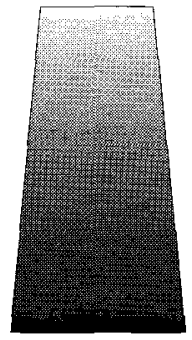

eg OP GABRIEL eg OP HANWOOD

eg OP CORPORATE

eg OP GRANBY

\section{Fig 1. Spectrum of Conflict}

expounds the adoption of manoeuvre warfare as the approach to the waging of high intensity conflict. As an approach, it is diametrically opposed to the plans for the deployment and employment of the old 1(BR) Corps. Many will recall that BAOR and NORTHAG were committed to an essentially attritional battle against the first operational echelon of the Warsaw Pact. The Second operational echelon were to be defeated by other NATO forces before resort to nuclear escalation. This was the strategy of flexible response(17). Basically, it was a deterrent posture rather than a warfighting option. Should a conflict have actually happened, then the stakes would have been so high, nothing less than national survival, that the expected large casualty rates were deemed acceptable.

The medical plan recognised that the battle would be a delaying operation which would gradually draw nearer to 
the echelons of hospital support. The nature, tempo and direction of the battle precluded the necessity for advanced resuscitation assets to be placed far forward. These would almost certainly have been overrun and lost. Instead, the surgical expertise was to be retained in the hospitals and a philosophy of therapeutic minimalism was considered reasonable. Given the scale of the casualty load and the political stakes being played for, such an approach was defensible and logical.

However, manoeuvre warfare differs markedly from the attritional basis of the 1(BR) Corps concept of operations. It is fundamentally a warfighting philosophy(18). Any deterrence value it possesses arises from the perception that an enemy will be beaten by its application. It seeks to exploit the uncertainties implicit on the battlefield(19). Opportunities to get inside the opponent's decision-action loop will be seized(20). This means that the speed, tempo and violence of the advance will be unlike anything which $1(\mathrm{BR})$ Corps was able to mount. It is an approach which recognises that the application of violence is the method of fashioning perception(21). The human aspect of the conflict is central to it and indeed, becomes the target of it. The enemy's perceptions will be affected at societal, individual soldier and at commander level. This is the entire aim of manoeuvre warfare.

The experience of Operation GRANBY underlined the effectiveness of manoeuvre warfare. It was a classic exposition of the method. It also highlighted a number of problems for the medical services in supporting such a high intensity limited war(22). Clearly, the speed of the advance and high tempo of the operation led to long distances in the CASEVAC chain. The availability of air assets to bridge this growing gap between point of wounding and hospital care was problematical, and the initial recovery of casualties from the battlefield was also difficult. The end result was a delay in hospital care for some. In terms of the physiology of trauma, distance equals time and time requires resuscitation either with or without holding of patients. The alternative is avoidable morbidity and mortality.

\section{Medical Implications of Manoeuvre Warfare}

Clearly, if medical support is to meet the new requirements of manoeuvre warfare then much of the tactical thinking left over from 1(BR) Corps will need to be revisited. The almost infinite tactical variability existing on the modern battlefield arising from manoeuvre warfare's commitment to exploit the individual commander's initiative and innovation, mean that a template solution to the provision of medical support is impossible. Instead, a return to basics with a restating of principles is necessary. These can then be developed into a concept and modified as required to each new tactical scenario.

The first and paramount requirement is to define the desired clinical outcome. In terms of trauma management, this is relatively easy because of the universal acceptance of the ATLS philosophy. If this is the norm, let alone the gold standard, for the initial management of traumas patients in civilian professional practice and, if it is . proven to improve morbidity and mortality rates, then if . should form the basis for battlefield trauma managemento It is now generally accepted that ATLS does indeed meet? these criteria. Indeed, the introduction of BATLS as the्ञ military variant is acceptance of this very point.

In physiological terms, BATLS and Battlefieldo Advanced Resuscitation Techniques and Skills (BARTS) seek to exploit at the earliest instant the opportunity to 8 initiate resuscitation, with this expertise being available close to the point of wounding. Given the trimodaf? distribution of death on the battlefield, the intention is to bite into the second peak. If this can be successfully $\vec{\omega}$ achieved, then not only will mortality rates be improved the longer term morbidity will also be favourably affected. Ultimately, the aim of BATLS/BARTS is to present a live patient to the surgeon.

However, there will continue to be a proportion of casualties whose condition will not be remedied by the ATLS approach. This proportion will probably lie between 10 and $20 \%$ of all P1 casualties(23). These BATLS failures are almost certainly those individuals suffering from a major leak in the vascular tre. Eventually, they will succumb to haemodilution am exsanguination. Their hypovolaemic shock cannot sim be remedied by constant administration of intravengi fluids $(24)$. They will require a surgeon to intervene $4 \vec{t}$. order to solve the problem of haemorrhage. In additiog they will need that intervention early on if complications of shock are to be avoided. This requisis guaranteed early access to the necessary surgery. The nature of that surgery is different from the traditiona approach. It is based on the work pioneered by $\operatorname{Mattox}(25 \stackrel{\circ}{\mathrm{Q}}$ 26, 27).

Working in Houston, Mattox was frequently faced by need which overwhelmed his resources. The numbers of patients suffering from gunshot wounds, including high velocity weapons, were such that the surgical team could not cope. Hence the concept of damage control surgery was developed. Only sufficient was done to ensure the continued survival of the patient until more definitive treatment was available. Examples of this approach would be the packing of the hepatic bed to stem haemorrhage Closure could be accomplished by towel clip or opsite When resources become available, then a more extensive surgical procedure would be performed.

Mattox noted that this approach improved his surviva? rates, not only by allowing a more sensitive triage process? to be completed, but also by allowing some of the physiological problems associated with resuscitation to beㅡ. tackled. Implicit in this approach is a commitment to newn and novel working practices. Thus, the initial surgery would be titrated against the anaesthetist's assessment Once the anaesthetist is content that the patient has ancw adequate cardiorespiratory status, then closure is effected 
The aim of the surgical resuscitation is to give time for the individual to receive more definitive treatment(28).

For surgical resuscitation to be successful on the battlefield it requires the development and application of protocols. These will be essential to ensure that time is not wasted. Only sufficient to enable the casualty to receive more extensive treatment at a more static and extensively equipped facility is necessary. Any more will ground the FST and deprive it of its essential mobility. Clearly, for this to work the clinicians involved will have to be widely experienced. The necessary degree of expertise requires judgement as well as appropriate operative experience. It is a clinically defining and determining point and should not be undertaken by the inexperienced. Equally, it will be readily perceived that this philosophy completely negates the current 6 hour rule and 7 to 10 day restriction on moving certain postoperative patients. The approach embodied in these two concepts does not sit easily with surgical resuscitation and predates many of the modern therapeutic and continuing care techniques. Useful as they may have been in the past, they are now at best irrelevant and at worst positively unhelpful. Maximum exploitation of time is the crucial factor not the imposition of delay.

Once surgical resuscitation has been performed then the casualty's condition will need adequate intensive care. It must be borne in mind that these casualties represent a departure from the traditional surgical template. These are individuals who would previously have died, either on the battlefield or in the medical chain. Now, they are salvageable but very sick. Self evidently, such care demands high technology, a stable platform and a controlled environment in which it can be provided. It will also require a shift from the previous philosophy of therapeutic minimalism.

The whole provision can be viewed as a triad; BATLS as soon as possible; surgical resuscitation as soon as possible for BATLS failure; field intensive care for all who need it. The system is a reflection of the existing civilian model but is only partially in place on the battlefield. There are significant shortfalls in the current military system. Having established the desired clinical outcome, it is necessary to review the tactical constraints. The synthesis of the two will then determine the nature of the medical concept of operations.

Since time is a major determinant of clinical success in resuscitation, it is essential that speedy access to BATLS is possible. At the moment this is problematical for a variety of reasons. Firstly, present mandatory first aid training is adequate to deal with the essentials of immediate treatment. However, it is based on self aid or "buddy aid". The idea of a colleague stopping in the assault to provide such treatment is not reasonable. The mission is the paramount concern and this means in the close battle the physical assault of the enemy. No avoidable diminution of combat power is acceptable at that critical stage. There have been instances when this has been observed and an adverse tactical result has followed. On the other hand from the perspective of the injured individual, the early initiation of treatment is essential. Hence, due to the tactical imperative, there is a potential delay in entry to the triad system.

Similarly, dependent upon the terrain and time of the close battle, it may be extremely difficult even to locate a casualty. This is particularly true of a dismounted infantry assault. Experience in the Falklands Conflict confirmed this point(29). Fortunately, there is a possible solution to this double difficulty.

Presently, most of the musicians embodied into the new band structure have roles as in-transit medical attendants (ITMA). It may be more appropriate for them to be deployed to field ambulance COs (under operational control), in order that they can be used forward at role one in accordance with the defined main effort. This will require them to be trained up to ATD5 standard and to be employed as stretcher bearers which has been a traditional and historical role for them. Their current role as ITMA could more appropriately be performed by Territorial Army combat medical technicians and nursing officers. The proposal embodies training advantages for all the groups involved as well as tackling, at least in part, the perpetual under-resourcing of role one medical assets.

In tandem with this redeployment, the proportion of combat medical technicians serving in the combat arms needs to be raised. Additionally, these individuals will require to be BARTS trained. Fortunately, steady if slowo progress has been made on this manning situation whilst all medics now routinely undergo BARTS training on theo ? completion of class one trade training. The overall situation is improving.

Surgical resuscitation will demand the forward deployment of Field Surgical Teams (FSTs). It is impossible to guarantee rapid CASEVAC on the battlefield. The nature of the battle precludes it. This means that the surgical facility has to be brought to the casualty. Again, this is a solution which has its precedents. Mobile FSTs were used in the North Africa(30) campaign against Rommel, as well as the breakout from Normandy. It is essential to provide the correct balance of support and mobility to this surgical grouping in order that the necessary clinical intervention can be achieved. Again there are precedents both historical and contemporary. It needs to be understood that whilst manoeuvre warfare seeks to exploit enemy vulnerabilities, it does not prevent him from reciprocating. Thus, the temporary hazard of an open flank may have to be accepted in order to seize a fleeting opportunity. Implicit in this is a readiness to accept the risk of a portion of the force being isolated. Clearly, this situation is similar to that faced by airmobile and airborne formations in their concept of operations.

In this context it is useful to examine the methods in which the twin problems of battlefield isolation and problematical casevac have been tackled. The composition of the Parachute Clearing Troop (PCT) of 23 
Parachute Field Ambulance gives a suitable model(31). The component parts may include two FSTs, two sections, a treatment section element and supporting elements. The PCT is a tactical grouping whose exact composition will vary in accordance with changing missions and battlefield conditions.

The concept is well proven and has immediate relevance to the rapidly mobile and fluid nature of high intensity combat. For an armoured battle there will also be the need for additional sections and ambulance assets with command being based on the Forward Squadron Headquarters. This Advanced Dressing Station (ADS) should normally be no more than 5 kilometres from the Regimental Aid Post (RAP). Such forward siting allows the time from initiation of BATLS to recognition of its failure and its surgical correction, in the least time tactically possible.

Onward evacuation clearly becomes a crucial factor. Those P1s who have undergone surgical resuscitation will be extremely ill. They will require not only speedy but also smooth evacuation means. This can be provided by the light utility helicopter, currently the Lynx. Only one aircraft will be needed because of the estimated casualty rates. This may make it more likely to be dedicated and fitted for role since it will not demand the opportunity retasking of a substantial support helicopter force. The proposal becomes feasible as well as being specifically tailored to the medical requirement. Crewing of the helicopter will have to be complemented by fully trained medical staff. The clinical task will be demanding since the casualties will be immediately postoperative following surgical resuscitation, with all of the possible attendant problems. Figure 2 outlines the concept.

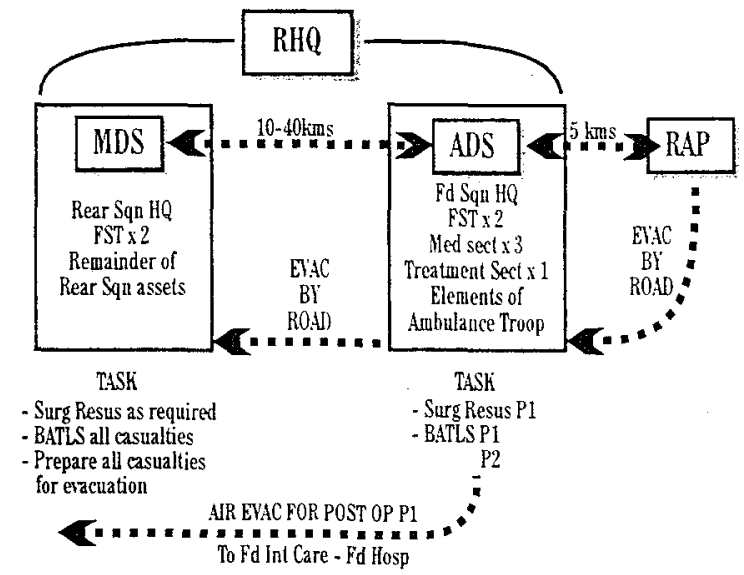

Fig 2. Concept of Surgical Resuscitation at Role 2

On arrival at field hospital the casualty will require a mixture of pre-operative intensive care, surgical treatment and postoperative intensive care. The whole process is clearly resource intensive. It also implies that this facility will be at least relatively fixed. Treatment on this scale cannot be provided in a mobile and moving environment.
It also requires considerable scales of laboratory, medical imaging and monitoring equipment. Even with miniaturisation the $\log$ istic bill is likely to be considerable, particularly with respect to redeploying the $\mathrm{O}$ surgical and intensive care complex. Thus, it will form ac fixed point into which casualties will flow. As far as $\Rightarrow$ deployment goes, it may be necessary to invest the $\stackrel{\vec{S}}{\rightarrow}$ intensive care capability in a number of field hospitals, dependent upon projected casualty load and flow. Equally,

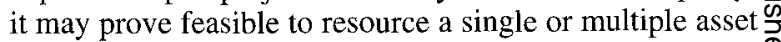
resembling the US Army Mobile Army Surgical Hospital (MASH) and to incorporate it as a module into an existing $\stackrel{\oplus}{\%}$ field hospital. This would have the added attraction of $\vec{\circ}$ enhanced flexibility of deployment options.

The fundamental principles on which the triad is based $\vec{\omega}$ can be summarised as grouping forward, grouping early and maintaining balance. It is believed that this combination of factors will allow trauma management to meet the dual challenges of high tempo and rapidly $\vec{P}$ mobile operations.

\section{Conclusion}

Many of the elements of the triad are either already in place or are planned. The progress has been by evolutiote Whilst this has the theoretical advantage of opportunio for consideration and reflection before implementation, $\frac{3}{4}+\frac{9}{0}$ tends to be incremental in its adoption and developmes. This does not match the pace of advances in either technology or techniques. Hence, there is always an element of lag which will increase the risk of a lack off. coherence in the underlying philosophy. Arguably, this $\mathrm{Is}$ exactly the situation at the moment. Different professionat groups are quite naturally trying to improve the capability in their area of expertise. The missing element is the overview of the requirement and an overarching doctrine. $\mathbb{Q}$

Faced with the likelihood of a declining resource base, $\overrightarrow{\vec{P}}$ it is imperative that this doctrinal void is filled. The 3 management of trauma on the high intensity battlefield is of central medical importance and holds considerableo. political significance. The implementation of the triad approach would move substantially in the right direction giving a coherence and logic to trauma care which would be instantly recognisable to a civilian trauma surgeon.

It also has the benefit of meeting a perceived ethical problem. During the transition to war stage, medical support is essentially based on peacetime practice. Whilst the overall operational imperative is one of force levelo maintenance, at the level of the clinician, the ethicalo approach is deontological(32). This orientation focuses the doctor's attention on doing the very best for the individual patient. This is the essence of the traditional $\frac{7}{0}$ doctor-patient relationship. Inevitably, the doctor uses his peacetime norms in diagnosis and therapy. There is a o $^{\circ}$ mismatch between this approach and the extant medicaln scaling. Medical equipment and scaling is designed forN general and high intensity war. Its contents have been repeatedly reviewed in order that this difficulty might be 
reconciled. However, once the line of departure has been crossed then the clinical approach alters. It is now more overtly utilitarian(33). The greatest good for the greatest number is the prevailing approach. Indeed, this is a belief which is at least partly enshrined in the process of triage. Reconciling the two competing philosophies is difficult.

However, as far as trauma management is concerned there is no need to switch ethical codes. The approach is the same whether the casualty is caused by enemy action in the close battle or by a road traffic accident in the preparatory phase to battle. It resolves the ethical dilemma. It also may point the way for a more general solution to this difficulty. Since the triad is based on harmonising operational and peacetime approaches, it might be possible to extend that method on a more general basis. Rather than have a treatment schedule determined by stockholdings of equipment, it should prove possible to develop the desired clinical outcome/tactical constraint model in order to define treatment regimens and the necessary equipment support.

Medical care is a crucial component of sustaining the battle. It has implications in the areas of force maintenance, maintenance of morale and ensuring popular support. The simplistic approach based on therapeutic minimalism does not meet the requirement fully in any of these areas. At best is only partly meets them. As an approach, such minimalism is still based on the deterrent approach of the Cold War rather than the new realities of manoeuvre warfare and limited war. Instead, a radical reappraisal of the philosophy of action is required and the triad approach presents a suitable alternative model.

\section{REFERENCES}

1. Macdonald H. Soviet Conduct: Western Interests. In The Soviet Challenge and the Structure of European Security. Aldershot: Edward Elgar, 1990; 213-254.

2. Messenger C. The Century of Conflict. Glasgow: Harper Collins, 1995; 376-395.

3. Statement on Defence Estimates. HMSO, 1995.

4. von Clausewttz C. On War. Howard M and Paret P, Eds. Princeton: 1976; 148-149.

5. NAPOLEON in Warrior's Worlds. Tsouras PG, Ed. London: Cassell, 1994; 204.

6. Ascoli D. The Mons Star. Bodmin: Harrap, 1982; 1 20.

7. Lawrence J, Lawrence L. When the Fighting is Over. London: Bloomsbury, 1988: 39-46.

8. McKeown T. The Medical Contribution. In Health and Disease: A Reader. Davey B, Gray A and Seale C, Eds. Open University Press, 1995: 182-190.

9. Strassburg MA. The Gobal Eradication of Smallpox. In Health and Disease: A Reader. Davey B, Gray A and Seale C, Eds. Open University Press, 1995: 231236.

10. Department of the Army. Vietnam Studies - Medical Support 1965-1970. US Government Printing Office, 1974: 174-175.
11. DieHL PF. International Peacekeeping. Baltimore: John Hopkins, 1994: 184-190.

12. TAYLOR PM. War on the Media. Manchester, 1992: 130.

13. Lloyd C. The Case for the Media. In Defence and the Media in Time of Limited War. Young PR, Ed. London: 1992: 44-68.

14. DunCAN ADA. Mixing the Media: Guidelines for Commanders. British Army Review 1995; 110: 17-26.

15. Medical History of the Second World War. Cope Sir Z, Ed. HMSO, 1953: 1-8.

16. Design For Operations: British Military Doctrine. HMSO. 1989.

17. MYERS KA. NATO: The Next Thirty Years. London;Westview, 1980; 41-148.

18. Thomas INA. Manoeuvre Warfare - Its Place in British Military Doctrine. British Army Review 1995;100: 75-83,

19. Hooker RD, Ed. Manoeuver Warfare - An Anthology. Presidio, 1993: 3-18.

20. HOOKER RD, Ed. Manoeuver Warfare - An Anthology. Presidio, 1993: 57-75.

21. HOOKER RD, Ed. Manoeuver Warfare - An Anthology. Presidio, 1993: 142-187.

22. LiLLYwhite LP, Leitch RA. Medical Support. In Gulfo Logistics - Blackadder's War. White M, Ed. London: Brasseys, 1995; 77-114.

23. Kirby N, Blackburn G. Field Surgery Handbook HMSO, 1981: 4-6.

24. Bicknel.. WH, Wall MJ, PePe PE, et al, Immediate versus delayed fluid resuscitation for hypovolaemic patients with penetrating torso injuries. $N$ Engl J Med 1994; 331: 1105-1109.

25. Hirshberg A, Wall MJ, Mattox KL. Planned reoperation for trauma: a two year experience with 124 consecutive patients. J Trauma $1994 ; 37$ : 365369.

26. Burch JM, ORTIZ VB, Richardson RJ, et al. Abbreviated laporotomy and planned reoperation for critically injured patients. Ann Surg 1992; 215: 476483.

27. Hirshberg A, Wall MJ, Ramchandani MK, et al. Reoperation for bleeding in trauma. Arch Surg 1993; 128: 1163-1167.

28. Hirshberg A, Mattox KL. Damage Control in Trauma Surgery. Br J Surg 1993; 80: 1501-1502.

29. ADKIN M. Goose Green. Leo Cooper, 1992: 211-250.

30. Medical History of the Second World War - Surgery. Cope Sir Z, Ed. HMSO, 1953: 9-45.

31. LILLYWHITE LP. Medical Support of Airborne Operations, JR Army Med Corps, 1988; 134: 59-64.

32. Beauchamp TL, Childress TF. Principles of Biomedical Ethics. Oxford: 1994; 56-61.33.

33. Beauchamp TL, Childress TF. Principles of Biomedical Ethics. Oxford: 1994; 47-56. 